\title{
Role of manufacturing towards achieving circular economy: The steel case
}

\author{
Wang, Peng; Kara, Sami; Hauschild, Michael Zwicky
}

\section{Published in:}

C I R P Annals

Link to article, DOI:

10.1016/j.cirp.2018.04.049

Publication date:

2018

Document Version

Peer reviewed version

Link back to DTU Orbit

Citation (APA):

Wang, P., Kara, S., \& Hauschild, M. Z. (2018). Role of manufacturing towards achieving circular economy: The steel case. C I R P Annals, 67(1), 21-24. https://doi.org/10.1016/j.cirp.2018.04.049

\section{General rights}

Copyright and moral rights for the publications made accessible in the public portal are retained by the authors and/or other copyright owners and it is a condition of accessing publications that users recognise and abide by the legal requirements associated with these rights.

- Users may download and print one copy of any publication from the public portal for the purpose of private study or research.

- You may not further distribute the material or use it for any profit-making activity or commercial gain

- You may freely distribute the URL identifying the publication in the public portal

If you believe that this document breaches copyright please contact us providing details, and we will remove access to the work immediately and investigate your claim. 
Role of manufacturing towards achieving circular economy: The steel case

Peng Wang ${ }^{a}$, Sami Kara $(1)^{a, *}$, Michael Z. Hauschild (1)

a Sustainability in Manufacturing and Life Cycle Engineering Research Group, School of Mechanical and Manufacturing Engineering, The University of New South Wales, Sydney, Australia

${ }^{\mathrm{b}}$ Division for Quantitative Sustainability Assessment, Department of Management Engineering, Technical University of Denmark, Lyngby, Denmark

* Corresponding author, e-mail address: S.Kara@unsw.edu.au.

\section{Abstract}

Circular economy (CE) has been promoted worldwide as a strategy to reduce material use and to increase the material use efficiency by closing material loops at the societal level. The core concept of CE is to improve the circularity of material use through turning materials at the end of their service life into resources for others, however, there is very little information about the role of manufacturing in achieving CE. Using the concepts of dynamic material flow analysis and stock dynamics, this paper proposes a methodological approach to help understand the role of manufacturing in achieving CE. A number of other strategies such as material efficiency in conjunction with CE are also tested using the case of global steel use to draw conclusions.

Keywords: Sustainable development, Manufacturing, Circular economy

\section{Introduction}

As resources become scarcer and associated impacts rise, the linear pattern of 'take, make and dispose' in industry and society calls for a change. In this context, circular economy (CE) has gained significant attention among global stakeholders including manufacturers [1-4]. The core concept of CE is to improve the circularity of material use (i.e. recycling, remanufacturing, reuse, etc.) throughturning materials at the end of their service into resources for others [3,4]. Nevertheless, this End-of-Life (EoL)-based CE has been criticized recently on its the feasibility of implementation [5], cost competitiveness [6], rebound effect [2], effectiveness [7], etc. Hence, a holistic investigation is highly demanded.

Materials are essential for manufacturers to produce various products. Meanwhile, decisions from manufacturers regarding selection and use of materials in their corresponding activities strongly affect the way how the material is processed in its entire life cycle stages (i.e. production, manufacturing, use, and recycling). Over the past decades, manufacturers have developed and promoted various concepts (e.g. efficient manufacturing [8], eco-design [9], etc.) embodied in life cycle engineering (LCE) [10] to manage the corresponding products and materials from a life cycle perspective. Nevertheless, only limited LCE tools have been included to assist the CE. Herein, the Cradle to Cradle design framework proposed by Mcdonough and Mcdonough [4] is a perfect example which aims to design the product in a way that enables the waste in the EoL stage to become a resource for manufacturing of another product at the same or higher level (upcycling). However, from a broader systematic perspective, the contribution of manufacturers in achieving

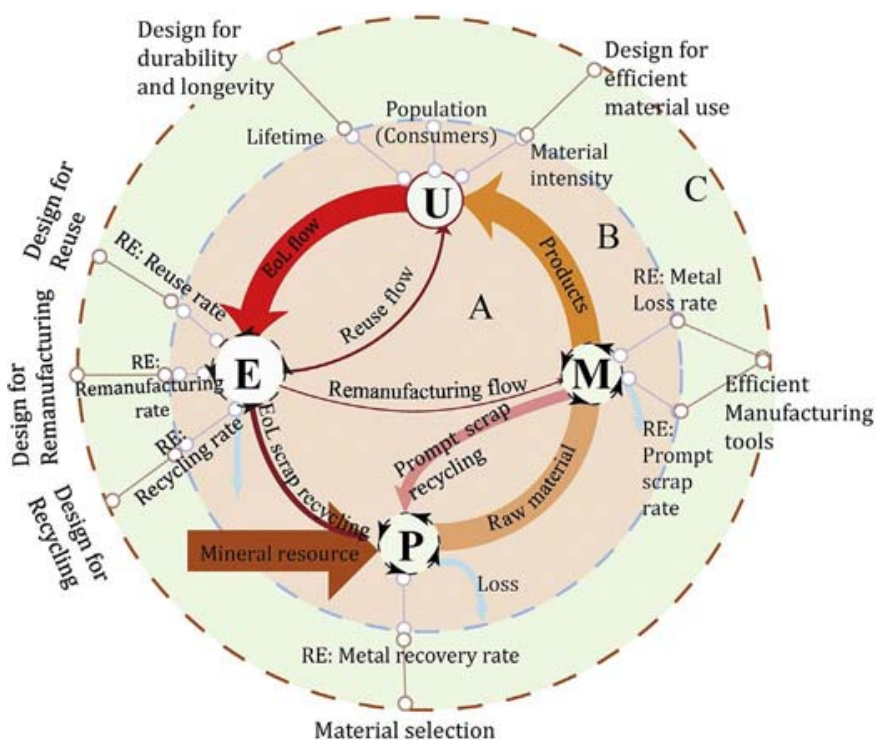

CE has not been well studied and appreciated. Hence, this studyaims to reveal the critical role of manufacturers in achieving $\mathrm{CE}$ from a life-cycle based framework.

Such investigation requires a quantitative description and prediction on how materials are fed, processed, stored, and recycled inside the anthropogenic material cycle (AMC). Among all involved methods [10], the industrial ecology provides two well-established tools to serve this aim, i.e. dynamic material flow analysis (MFA), and stock dynamics. Herein, the dynamic MFA can systematically quantify the inflow, outflow, and loss of a given material in a process or system over some period [11] based on the mass balance principle. Stock dynamics helps to depict the mechanism in end-of-life material flow generation and explore drivers in the growth of material in-use stocks, defined as the sum of material in all included in-use products [12]. Dynamic MFA and stock dynamics have been combined as a powerful tool to predict the future global material stocks and flows in its anthropogenic cycle under different scenarios [12].

Iron and steel (henceforth described as steel) is selected as case study to explore the role of manufacturing in achieving CE. Steel is chosen because (a) it is the world's most used metal for manufacturing of various products and (b) as a metal it can retain its utility after multiple runs of recycling and is acknowledged as the world most recycled metal [13]. Hence, with abundant studies available [6,14,15], this study can provide convincing results on how manufacturing contributes towards achieving CE, rendering the steel case a useful exemplary case for other materials in CE study.

\section{Methodology}

\subsection{Life cycle framework}

Implementation of circular economy can be monitored through the information of routes and magnitude of material in its anthropogenic cycle. The corresponding decisions and activities (e.g. LCE tools) from manufacturers can have profound impacts on the entire life cycle stages, which includes but not limited to (a) determining the material flows and losses inside manufacturing, (b) selecting 'cleaner' material from more efficient producers, (c) improving the product design with less material use for same service and for durability and longevity; and (d) designing products for reusability, recyclability, and remanufacturing.

Therefore, a novel life cycle framework to link the LCE tools and $A M C$ is shown in Fig. 1. Within the framework, three subsystems are integrated. Sub-system A (the anthropogenic material cycle) is located at the center of this framework which presents the material stocks and flows along its life cycle. Sub-system B (material cycle indicators) comprises the major indicators in determining the material stocks and flows in the anthropogenic cycle. Sub-system C (LCE tools) is located at the outer ring of this framework, and some representative LCE tools are selected and allocated to each life cycle stage. 
tools (e.g. MFA) [16] to depict the material stocks and flows in the anthropogenic cycle which includes four major life cycle stages: i.e.material production, manufacturing, in-use, and endof-life. Apart from the linear flows from one stage to its following stage, four circular routes of scraps (i.e. prompt scrap recycling, reuse, remanufacturing, and recycling of EoL scrap) have also been captured in the framework. This study follows the basic dynamic MFA procedure [14,17]. For three of the life cycle stages (i.e. material production, manufacturing, and end-oflife), the mass-balance principle is applied to obtain the material inflow, outflow, and loss at the time $t$ for stage $k$;

$$
\begin{array}{r}
\text { Outflow }(k, t)=\operatorname{Inflow}(k, t)-\operatorname{loss}(k, t) \\
=\operatorname{Inflow}(k, t)-R E(k, t)
\end{array}
$$

The Eq. (1) can be solved for (a) outflow using production statistics (e.g. world steel yearbook) of each unit stage, (b) inflow using the mass balance with production statistics in the upstream and downstream unit stage, (c) loss using the mass balance of inflow and outflow, and (d) resource efficiency $(R E)$ of this unit stage, defined as the mass ratio of outflow to inflow.

Meanwhile, for the in-use stage, its outflow is determined by using historical inflow to in-use stage and use lifetime of different products. The well-established lifetime distribution approach $[14,17]$ is applied:

$$
\operatorname{Outflow}(t)=\int_{1900}^{t} \operatorname{Inflow}(x) \times f(x, \tau, \omega) d x
$$

where $f(x, \tau, \omega)$ is the probability densities of the lifetime distribution function (assumed to follow Weibull distribution [12] here), $t$ is the lifetime of the product $x, t$ is the current time, and $\omega$ is the lifetime distribution parameter. The detailed step-by-step calculation for each stage can be found in Refs. $[11,15]$.

\subsection{Depicting the impact of LCE tools on material flow analysis}

The overall study includes the historical quantification and future projection. The indicators shown in sub-system $B$ of Fig. 1 are quite critical for this quantification as they determine the performance of the AMC [11]. There are $6 \mathrm{RE}$ indicators that reflect the efficiency of LCE tools (metal recovery rate, recycling rate, etc.) and 3 in-use based indicators representing central aspects of the in-use stage (number of consumers, material intensity of the consumption and lifetime of products). For the historical quantification, values for those indicators are obtained directly from the mass ratio of outflow to inflow or statistics. As for the future projection, those indicators are exogenously given in scenario settings. More detailed scenarios are set based on the change of those indicators driven by the corresponding LCE tools. Moreover, the future projection is conducted with the well-established stock dynamics approach [14]. The final step is to compare the results in those scenarios with the basic scenario to gauge the impact of LCE tools in achieving CE.

\section{Steel case and scenarios settings}

Case study requires various input parameters (i.e. $6 \mathrm{RE}$ indicators and 3 in-use based) as introduced in Section 2.3. For the historical quantification, the study directly adopted the results on historical material flows and stocks from previous work for the year 1900-2013 [11], in which those key indicators, and the historical demand and in-use stocks were obtained. For future projection, those input parameters are assumed in various scenario settings in Table 1, which involves three elements: population trend estimation, per capita material in-use stock growth, and changes in other key indicators as follows: (a) the future population is based on the medium scenario in "World Population Prospects" published by United Nations Population Division [18]. (b) The material intensity is allocated to the per capita basis using the per capita in-use stock as the proxy. The future trend of in-use growth is estimated based on the saturation hypothesis [17] which observed that most developed countries follow a similar saturation pattern of per capita in-use stock growth. The saturation level is around 13.4 tons steel per capita. Finally, (c) the changes in key RE indicators and lifetime of products are determined by the scenario settings.

Moreover, a product-specific treatment is applied to obtain more detailed results in three life cycle stages (i.e. manufacturing, in-use, and end-of-life), which are quantified based on four major categories of steel final products (i.e. construction, vehicles, machinery, and durable daily goods and others).

Table 1 gives the information of the specific scenarios and the settings of key indicators for the steel case allocated to each life cycle stage. This study applies two main scenarios, i.e. baseline scenario (BLS) and LCE scenario (LCES): BLS represents a business-as-usual estimation of future trends without additional policy intervention, and LCES includes the implementation of LCE tools to improve the material use along its full life cycle. To clarify the stage-specific impact of those LCE tools, seven sub-scenarios were proposed to integrate the LCES (as shown in Table 1). Based on detailed studies in Refs. $[14,15,17]$, the current value and future potential values can be obtained for the steel case for most MFA indicators. With the attention and implementation of LCE tools, this study assumed that they can reach their full potentials in 2050 which is similar with Ref. [17]. It is noted that two indicators (i.e. remanufacturing rate and reuse rate) have not been modeled in AMC studies for the unrecycled EoL amount. Herein, this study included these indicators in our AMC quantification to fit the framework in Fig. 1, and their future trends are assumed to be increased with the same value $(12 \%)$ as the recycling rate improvement since they are all included in the end-of-life stage. 


\begin{tabular}{|c|c|c|c|c|c|c|c|}
\hline Lifecycle stage & Key indicators & 2013 & 2050 & 2100 & LCE tools & Scenarios & Abbreviation \\
\hline \multirow{4}{*}{$\begin{array}{l}\text { Material } \\
\text { production }\end{array}$} & \multirow{4}{*}{$\begin{array}{l}\text { Metal recovery rate for ore-based } \\
\text { material production } \\
\text { Metal recovery rate for } \\
\text { scrap-based production }\end{array}$} & $70 \%$ & $70 \%$ & $70 \%$ & None & Baseline scenario & BLS \\
\hline & & $70 \%$ & $73 \%$ & $73 \%$ & Material selection & Efficient material production & EMP \\
\hline & & $94 \%$ & $94 \%$ & $94 \%$ & None & Baseline scenario & BLS \\
\hline & & $94 \%$ & $97 \%$ & $97 \%$ & Select low-impact materials & Efficient material production & EMP \\
\hline \multirow[t]{2}{*}{ Manufacturing } & \multirow{2}{*}{$\begin{array}{l}\text { Resource efficiency in } \\
\text { manufacturing }\end{array}$} & $87 \%$ & $87 \%$ & $87 \%$ & None & Baseline scenario & BLS \\
\hline & & $87 \%$ & $92 \%$ & $92 \%$ & Efficient manufacturing & Efficient manufacturing & EMN \\
\hline \multirow[t]{4}{*}{ In-use } & \multirow[t]{2}{*}{ Desired service level } & \multicolumn{3}{|c|}{$\begin{array}{l}\text { Follow the developed } \\
\text { countries' pattern }\end{array}$} & None & Baseline scenario & BLS \\
\hline & & \multicolumn{3}{|c|}{$\begin{array}{l}\text { Saturating at } 77.5 \% \text { of } \\
\text { developed countries' } \\
\text { level }\end{array}$} & $\begin{array}{l}\text { Design for less material for } \\
\text { same service }\end{array}$ & Efficient material use & EMU \\
\hline & \multirow[t]{2}{*}{ Product lifetime } & \multicolumn{3}{|c|}{$\begin{array}{l}\text { Keep the lifetime same } \\
\text { for products }\end{array}$} & None & Baseline scenario & BLS \\
\hline & & \multicolumn{3}{|c|}{$\begin{array}{l}\text { Increase the lifetime to } \\
\text { its potential }\end{array}$} & Design for durability & Longer use lifetime & LUL \\
\hline \multirow[t]{6}{*}{ End-of-life } & \multirow[t]{2}{*}{ Recycling rate } & $78 \%$ & $78 \%$ & $78 \%$ & None & Baseline scenario & BLS \\
\hline & & $78 \%$ & $90 \%$ & $90 \%$ & Design for recycling & Recycling scenario & RYS \\
\hline & \multirow[t]{2}{*}{ Remanufacturing rate } & $0 \%$ & $0 \%$ & $0 \%$ & None & Baseline scenario & BLS \\
\hline & & $0 \%$ & $12 \%$ & $12 \%$ & Design for remanufacturing & Remanufacturing scenario & RMS \\
\hline & \multirow[t]{2}{*}{ Reuse rate } & $0 \%$ & $0 \%$ & $0 \%$ & None & Baseline scenario & BLS \\
\hline & & $0 \%$ & $12 \%$ & $12 \%$ & Design for reuse & Reuse scenario & RUS \\
\hline AMC & All indicators & \multicolumn{4}{|c|}{$\begin{array}{l}\text { Changes of indicators in all scenarios } \\
\text { above expect BLS }\end{array}$} & Life cycle engineering & LCES \\
\hline
\end{tabular}

\section{Results and discussion}

\subsection{Future steel demand remains high and will be shifted} from ore-based to scrap-based resource

This study obtained the 9 sets of results (i.e. for 9 scenarios from BLS to LCES in Table 1) regarding annual steel stocks and flows along the AMC from 1900 to 2100 . Meanwhile, the results of the model have been compared with historical data of in-use stocks [15], and a good conformity (i.e. less than $\pm 2 \%$ in variation) is obtained. For the estimated years from 2014 to 2016, our results also give a relatively accurate result (less than $\pm 4 \%$ ) compared with official data in mining production [19]. Nevertheless, the prospective results are highly sensitive to the scenario settings. Hence, they should be considered as
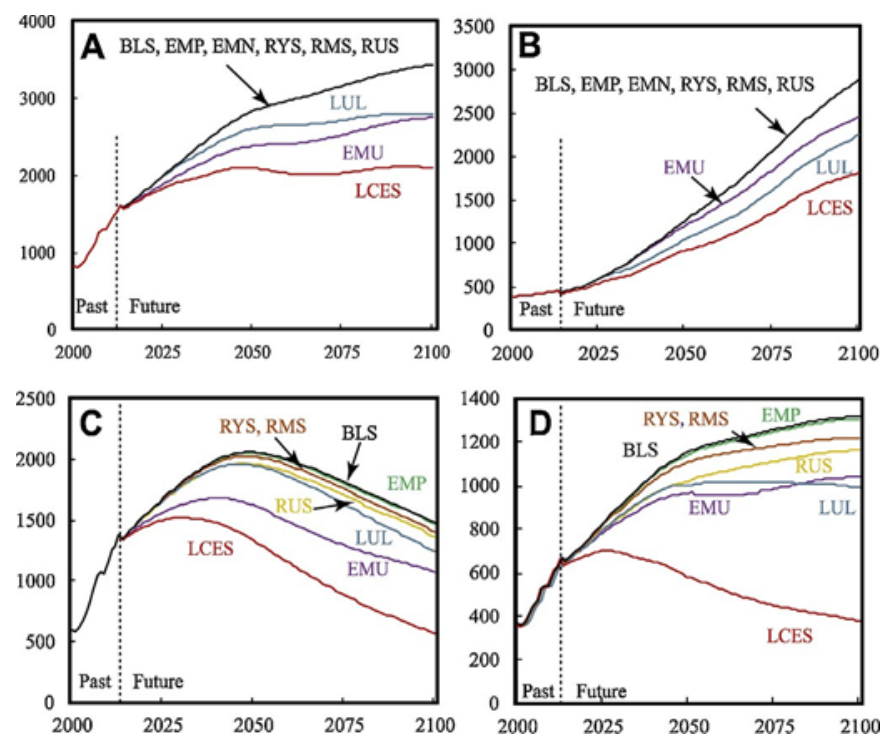

Fig. 2. Results for nine scenarios. (Note: (A) outflow from manufacturing (Mt/yr);

(B) end-of-life scrap generation (Mt/yr), (C) mining production (Mt/yr), (D) resource loss from all life cycle stages (Mt/yt), and Mt: million tons; yr: year.) indicative to reveal the relative impact of those strategies on future efficiency in AMC, rather than giving an accurate future prediction. With regards to production trends in manufacturing, findings need to be highlighted as follows:

(1) Despite the fact that steel has been consumed extensively in the past century, the demand for this material will continue to grow strongly in the future under any scenario setting. As shown in Fig. 2A, the steel manufacturing is expected to expand its capacity from two to four times at the end of this century compared to the level in 2000. The development of the population is one driver as it will increase from around 7 billion in 2013 to 11 billion in 2100 . Another factor, affluence, plays a more deterministic role as thein-usestock per capita increases much more significantly from 4 tons in 2013 to 12.3 tons (or 10 tons in EMU and LCES) in 2100. In this context, managing the life cycle of steel use efficiently gains extreme importance for manufacturers and other stakeholders. Indeed, compared with the BLS scenario, the scenarios of EMU and LCE can help to reduce future demand in 2100 by around 684 million tons per year (Mt/yr) and $1323 \mathrm{Mt} / \mathrm{yr}$, respectively, compared to around $3400 \mathrm{Mt} / \mathrm{yr}$ as total demand in BLS.

(2) The scrap-based material will dominate future material sources for manufacturing. All scenarios are expected to have more than $50 \%$ input as scrap at the end of this century, which will trigger a reverse trend for manufacturing from handling the ore-based material to the handling of scrap-based material, as already proposed in Ref. [14]. Hence, how to maintain and use the scrap becomes a critical future challenge for manufacturers.

\subsection{The importance and inadequacy of EoL-based strategies}

Material circularity needs to gain importance in the future as the EoL scrap keeps increasing unprecedentedly as shown in Fig. 2B. Steelalready has a good recycling performance thanks to the implementation of CE and other EoL-based strategies [13]. Nevertheless, steel still needs a better performance in recycling and reuse of scraps. As shown in Fig. $2 A$ and $B$, the EoL scrap generation is enough to fully satisfy the future steel demand. However, although the recycling rate of scraps reaches its maximum in several scenarios, the scrap still fails to entirely meet the steel demand.

In practice, recycling rates cannot reach $100 \%$ due to the limitations in collection, sorting, and separation in the recycling stage, and metal recovery in the production stage [20]. As a result, the more and faster the EoL scrap flows, the more resource will be lost and the higher impact will be caused by turning those scrap into resource. In other word, end-of-life strategies can be viewed as end- 
of-pipe solutions. This recognition reveals an inadequacy of EoL-based strategies which has barely been noticed before. Indeed, the current $C E$ package focuses excessively on the circularity of materials, mainly underlining the end-of-life activities (e.g. recycling, reuse, and remanufacturing in Ref. [4]). The reduction of EoL scrap generation should be prioritized since EoL-based strategies are shown to have a limited impact there. As shown in Fig. 2B, all circularity-oriented scenarios (i.e. RYS, RMS, and RUS-see Table 1) fail to reduce the end-oflife scrap generation compared with BLS.

\subsection{The need to expand the CE package by incorporating} strategies targeting the entire life cycle

Resource depletion and loss are two important indicators to gauge the efficiency of the entire anthropogenic cycle [11], which can give a broader view regarding the efficiency of a given strategy in improving anthropogenic material use. The trends of resource depletion (using mining production as a proxy) and resource loss in all scenarios are shown in Fig. 2C-D.

The material production and manufacturing stage-specific strategies (in scenario EMP and EMU) are slightly better than BLS in reducing resource depletion and resource loss. It should be acknowledged that the manufacturing stage has already been very efficient, and the potentials have nearly been fully achieved. Hence, the EMN scenario, which focuses on efficient manufacturing, has alimited impact. Meanwhile, the potential of EMP is constrained by the metallurgical limits in terms of metal recovery.

This study also reveals the significant contributions from inuse stage-specific strategies (i.e. efficient material use, and longer use lifetime) in promoting the performance of AMC. And this strategy is much more efficient than end-of-life stagespecific scenarios, and their potentials for improvement are also considerable [17]. With around $23 \%$ less material use, EMU can help to save around $250 \mathrm{Mt}$ ore use per year. Meanwhile, about $250 \mathrm{Mt} / \mathrm{yr}$ ore can be reduced by prolonging the lifetime of products to their potentials (which vary between product categories-see details in Ref. [17]).

The LCES scenario combines all studied strategies in above scenarios and has the best performance in reducing EoL scrap generation, reducing ore resource consumption, and reducing the resource loss from the $A M C$ as shown in Fig. 2B-D. Meanwhile, the joint implementation of all those life cycle tools in the LCES scenario can outperform any other scenarios by a huge advantage. For instance, the LCES scenario will consume around $560 \mathrm{Mt} / \mathrm{yr}$ ore in 2100 , which is just above half of the amount (around $1073 \mathrm{Mt} / \mathrm{yr}$ ) in the best singular strategy-LUL scenario (in Fig. 2C). These results demonstrate the importance of expanding the EoL-oriented CE to a life-cycle based CE.

\subsection{Role of manufacturing in leveraging life-cycle based CE}

The life-cycle based CE combines all strategies along the entire life cycle of products and material, and the manufacturing stage is at the center to foster those strategies. Inside the manufacturing stage, tools for efficient manufacturing [8] can help to save raw resources and minimize resource loss as shown in EMN in Fig. 2. Nevertheless, it should be acknowledged that strategies exclusively focusing on the manufacturing stage have limited potential and impact compared with the strategies focusing on other stages. Hence, manufacturers should be urged to expand their focus to the entire life cycle of material use applying their influence through the implementation of various LCE tools.

It is of vital importance to have a joint use of those life cycle tools. Nevertheless, this study reveals the huge differences on the impact of the LCE tools corresponding to the different life cycle stages of steel products. The EoL-based strategies are indeed preferable to the strategies inside factories. However, the strategies related to the in-use stage can greatly outperform EoL-based strategies because in-use strategies can not only reduce the EoL flow generation but also support the increasing affluence with less material use. Furthermore, manufacturing can greatly influence how products are designed, produced, and managed to satisfy the market needs. As a result, the concepts related to manufacturing (i.e. design for durability and longevity and better product designwith less material use) can play a great role. And corresponding new business models are further required.

\section{Conclusion}

There is a great importance and urgency to expand the focus of the circular economy from the end-of-life to the entire life cycle of products [21]. This can be implemented through LCE tools in the manufacturing stage as well as new value propositions in the business models. This recommendation builds on results obtained through the combination of two types of approaches in this work, (a) a general framework to clarify the role of LCE tools in managing the anthropogenic material cycle; (b) a quantitative method (i.e. dynamic MFA) to gauge the corresponding leverage of each LCE tool in the anthropogenic material cycle; and (c) their application to a case study to quantify the anthropogenic steel cycle annually from 1900 to 2100 . The results indicate that steel faces an unprecedented need in the future and that it is essential to implement CE strategies regardless that steel is already one of most recycled and efficiently used materials. Moreover, manufacturing efforts inside the factory have limited impact but manufacturing can apply strategies to promote lifecycle-based $C E$, especially strategies related to in-use stage. Hence, it is highly recommended to include the entire life cycle in the CE policy making and implementations around the world and involve manufacturers to play a core role in this effort.

\section{References}

[1] Lieder M, Rashid A (2016) Towards Circular Economy Implementation: A Comprehensive Review in Context of Manufacturing Industry. Journal of Cleaner Production 115:36-51.

[2] Zink T, Geyer R (2017) Circular Economy Rebound. Journal of Industrial Ecology 21(3):593-602.

[3] European Commission (2015) Closing the Loop-An EU Action Plan for the Circular Economy, European Commission, Brussels, Belgium.

[4] Mcdonough W, Mcdonough W (2002) Cradle to Cradle-Remaking the Way We Make Things, North Point Press, New York, NY, USA

[5] Allwood J (2014) Squaring the Circular Economy: The Role of Recycling within a Hierarchy of Material Management Strategies. Handbook of Recycling, Elsevier Inc., Waltham, MA.

[6] Wang P, Li W, Kara S (2017) Cradle-to-Cradle Modeling of the Future Steel Flow in China. Resources Conservation and Recycling 117:45-57.

[7] Pedersen G, Hauschild M (2016) Circular and Safe? The 6th International Symposium on Food Packaging, Barcelona, Spain. 16-18 November.

[8] Duflou J, Sutherland J, Dornfeld D, Herrmann C, Jeswiet J, Kara S, Hauschild M, Kellens K (2012) Towards Energy and Resource Efficient Manufacturing: A Processes and Systems Approach. CIRP Annals 61:587-609.

[9] Shu L, Duflou J, Herrmann C, Sakao T, Shimomura $Y$, De Bock $Y$, Srivastava J (2017) Design for Reduced Resource Consumption During the Use Phase of Products. CIRP Annals 66:635-658.

[10] Hauschild M, Herrmann C, Kara S (2017) An Integrated Framework for Life Cycle Engineering. Procedia CIRP 61:2-9.

[11] Wang P, Li W, Kara S (2017) Dynamic Life Cycle Quantification of Metallic Elements and Their Circularity, Efficiency, and Leakages. Journal of Cleaner Production 174:1492-1502.

[12] Müller E, Hilty L, Widmer R, Schluep M, Faulstich M (2014) Modeling Metal Stocks and Flows: A Review of Dynamic Material Flow Analysis Methods. Environmental Science Technology 48:2102-2113.

[13] World Steel Association (2016) Stee/-The Permanent Material in the Circular Economy, World Steel Association, Brussels/Beijing.

[14] Pauliuk S, Milford R, Mu D, Allwood J (2013) The Steel Scrap Age Environmental Science Technology 47:3448-3454.

[15] Pauliuk S, Wang T, Müller D (2013) Steel All over the World: Estimating In-use Stocks of Iron for 200 Countries. Resources Conservation and Recycling 71:22-30.

[16] Chen W, Graedel T (2012) Anthropogenic Cycles of the Elements: A Critical Review. Environmental Science Technology 46:8574-8586.

[17] Milford R, Pauliuk S, Allwood J, Müller D (2013) The Roles of Energy and Material Efficiency in Meeting Steel Industry $\mathrm{CO}_{2}$ Targets Environmental Science Technology 47:3455-3462.

[18] United Nations Population Division (2015) World Population Prospects (2015 Re-vision), United Nations, New York, USA

[19] Ober J (2017) Mineral Commodity Summaries 2017, US Geological Survey, Reston, VA, USA.

[20] Reck B, Graedel T (2012) Challenges in Metal Recycling. Science 337 (6095):690-695.

[21] Ellen MacArthur Foundation (2015) Delivering the Circular Economy: A Toolkit For Policymakers, Ellen MacArthur Foundation, Cowes, United Kingdom. 